\title{
Stigma and life satisfaction among out-of-school Korean youth: the mediating roles of self-esteem and depressive symptoms
}

\author{
Myong Sun Cho ${ }^{1}$ \\ Accepted: 10 July 2021 \\ (C) The Author(s) 2021
}

\begin{abstract}
The purpose of this study was to assess the extent to which self-esteem and depressive symptoms mediated the influence of stigma on life satisfaction among out-of-school youth in the Republic of Korea. Cross-sectional data were collected from 318 youth, aged 18 to 23 years $(20.67 \pm 1.12)$, who provided information on perceived stigma, self-esteem, depressive symptoms, life satisfaction, and personal characteristics. A hierarchical linear regression analysis was followed by a path analysis to investigate the mediation effects. Stigma was found to be negatively associated with life satisfaction. Self-esteem mediated the negative association between stigma and life satisfaction, while depressive symptoms mediated the positive association between stigma and life satisfaction. The path analysis results showed that the influence of depressive symptoms on life satisfaction had the largest path coefficient $(\beta=-0.60, p<.01)$ and the influence of self-esteem on life satisfaction also has a large path coefficient $(\beta=0.52, p<.01$ ). This study demonstrated that self-esteem and depressive symptoms are important to the relationship between stigma and life satisfaction. Implications are discussed regarding possible stigma-reduction strategies and interventions to help out-of-school youth integrate into society and lead successful and satisfying lives.
\end{abstract}

Keywords Life satisfaction $\cdot$ Depressive symptoms $\cdot$ Self-esteem $\cdot$ Stigma $\cdot$ Out-of-school youth

\section{Introduction}

According to the Institute for Statistics of the United Nations Educational, Scientific and Cultural Organization (UIS, 2019), about 258 million children and adolescents worldwide were not attending school in 2018. Some of these individuals never had a chance to go to school at all, while others dropped out early. Vast literature has discussed stigma, depressive symptoms, and other phenomena as causes of dropping out of school; however, there is a lack of research addressing stigma and depressive symptoms as consequences of leaving school early. Analogies with existing research can be drawn only with the utmost caution. "Early school leavers" refer to people aged 18 to 24 years who leave formal education/ training without attaining secondary qualification or its equivalent. One of the great disadvantages of early school leaving is that it has become a marker for social exclusion (De Graaf \&

Myong Sun Cho

msunny.cho@gmail.com

1 Department of Nursing, Kyungbok University, Gyeonggi-do, 425 Kyeongbokdae-ro, Namyangju-si 12051, South Korea
Van Zenderen, 2009). Ameliorating the situation is now a national priority in many countries - with the key goal of reducing the number of dropouts to less than $10 \%$ of all students (Ross \& Leathwood, 2013).

Under South Korean law (all mentions of "Korea" or "Korean" in this article refer to the Republic of Korea, also known as South Korea), "out-of-school youth" are youth aged 15-24 years who do not attend any school (Ministry of Gender Equality and Family, 2018). Compulsory education in Korea encompasses six years of primary and three years of lower secondary school. The Korean policy to reduce school dropout will include upper secondary levels by 2021 (Raimondi \& Vergolini, 2019). In 2017, Korea's school dropout rates in elementary, middle, and high school were $0.7 \%$, $0.7 \%$, and $1.6 \%$, respectively. This rate positively correlated with age, and it consistently increased over the past five years (Ministry of Gender Equality and Family, 2018). In one study, some of the reasons the youth gave for dropping out of school were, "Did not need to finish school for chosen career" (39.4\%), "Did not like to study" (23.8\%), and "Physical and mental health problems" (17.8\%). This indicates that for about one-sixth of the participants, mental health was a reason for dropping out of school (National Youth Policy Institute (NYPI), 2018). 
Research has compared dropouts and graduates and found that they differed with respect to depressive symptoms and life satisfaction (Liem et al., 2010). In Western settings, these differences - with adequate family and peer support — can be transitory; by contrast, owing to Confucian culture and societal characteristics, the adverse effects are usually more lasting in Asian countries (Hunt et al., 2002). Compared with students who stay in school, adolescents who drop out tend to be at greater risks of a wide range of problems such as poor overall health and well-being, high stress, depressive symptoms, and certain health challenges. Some of these challenges are insufficient nutrition, delayed physical development, dental caries, substance abuse, no involvement in physical activity for health and well-being, alcohol use, tobacco use, sexually transmitted diseases, and pregnancy (Cho et al., 2015; Park \& Kim, 2016) among South Korean adolescents. A sign of subsequent dropping out can be absenteeism, which can be seen as early as in kindergarten (Gottfried, 2014). Previous studies found that youth who did not graduate high school were more likely than graduates to experience depressive symptoms, and they were less satisfied with their lives and reported higher levels of psychological distress than did high school graduates (Liem et al., 2010). This can lead to stigma, similar to that experienced by individuals with mental illnesses (Mashiach-Eizenberg et al., 2013). South Korean high school dropouts (vs. completers) experienced more aggressiveness, insomnia, suicidal thoughts or attempts, and low self-esteem during the transition from being a student to adulthood because they were unprepared for joining the workforce and were relatively challenged by their families' and communities' expectations and the associated responsibilities (Kim \& Yang, 2017). Stigma can diminish individuals' identities (Goffman, 2009); it is characterized by exclusion or devaluation based on negative judgments (Scambler, 2009). Stigma thus becomes a social condition in which perceived characteristics are used to separate from a group those individuals who have such characteristics. Being a "dropout" is a characteristic of an early leaver and it is used to distinguish (stigmatize) those individuals and separate or exclude them from group membership. Stigma might psychosocially, physically, and mentally burden marginalized individuals (including school dropouts) by aggravating their health and well-being and by increasing their psycho-emotional stress (Rao et al., 2019). In Korea, about $98 \%$ of young adults have a high school diploma and hope to continue their education to find a successful career (Ministry of Gender Equality and Family, 2018).

In Korea's collectivist, Confucian culture, which highly values education, there is strong social pressure on those who lack degrees, and they are considered under-qualified for almost every occupation (Keum, 2008). Moreover, the collectivist nature of the Korean culture prioritizes the sense of belonging and the relationship within the group rather than individual rights. As a result, parents expect that a high level of education will lead to the success and well-being of their children (Jung, 2010). With this socio-cultural background, adolescents who drop out of school are stigmatized explicitly or implicitly by society, as well as by their families. Thus, stigma toward out-of-school youth might manifest as overt discrimination based on judgments that they are defective. The lack of alternative educational pathways for out-of-school youth and the policy focus on formal education and development further exacerbate the stigma associated with dropping out of school (Yun et al., 2015).

Adolescents and emerging adults are sometimes stigmatized and discriminated against by their peers because they are unusual in some ways, such as being obese (Freudenberg \& Ruglis, 2007; Mustillo et al., 2012), pregnant (Birchall, 2018), mentally ill (Pang et al., 2017), HIV positive, and/or a sexual minority (Watkins et al., 2014). Almost one-half $(47 \%)$ of out-of-school youth in the Republic of Korea have felt stigmatized in their relationships with peers, family members, and neighbors, which has led to the loss of friendships and unwarranted assumptions, distrust, pity, avoidance, and underestimation of their abilities (NYPI, 2018). In their transition to adulthood, out-of-school youth seemed less prepared to be adults than those who were in school, and their environmental and psychological vulnerabilities tended to put them at risk (Levine Coley et al., 2004). Dropping out of school influences dropouts' health and well-being and creates public health problems (Freudenberg \& Ruglis, 2007).

Out-of-school youth have reported feeling stigmatized as culturally deviant (i.e., departing from the accepted standards), especially with respect to social behavior (NYPI, 2018). Moreover, they have been stereotyped as unintelligent, unskilled, and/or maladjusted, and they tend to be unemployed or involved in crime because they dropped out of school (NYPI, 2018). Previous studies found that stigma negatively influences individuals' health as well as their societal opportunities, including educational, employment, and housing opportunities, and it interferes with an appropriate transition to adulthood (Hatzenbuehler et al., 2013; Pascoe \& Smart Richman, 2009). In a nationally representative sample of African American and Caribbean Black youth, stigma was found to be negatively correlated with self-esteem and life satisfaction (Seaton et al., 2010).

Life satisfaction is the way people feel about themselves in their lives, and it is often a protective factor against negative life events and an indicator of adolescents' psychological and social development (Fujita \& Diener, 2005). In 2016, the average life satisfaction score of Korean youth was 6.6 (out of 10 ), which was lower than the 7.6 average among Organisation for Economic Co-operation and Development (OECD) countries (OECD, , 2016). Life satisfaction is multi-dimensional, and among other things, it embodies health, socioeconomic status, stressful events and conditions, social relationships, depressive symptoms, and self-esteem (Gaziel et al., 2015). 
In accordance with the previously mentioned Korean characteristics, one study found that self-reported global life satisfaction was lower for Korean adolescents than for U.S. adolescents, and satisfaction with school contributed significantly to global life satisfaction only for Korean adolescents (Park \& Huebner, 2005). By contrast, the level of satisfaction with self was a stronger correlate of global life satisfaction for U.S. adolescents than it was for South Korean adolescents.

Among adolescents, life satisfaction tends to relate positively to self-esteem, whereas life satisfaction is negatively related to depressive symptoms and stress (Proctor et al., 2009). Recent research has suggested that major changes such as parental divorce or family problems (e.g., parental alcoholism) influence life satisfaction (Kim, 2019); however, life satisfaction is a resilient trait. As dropping out of school is a major change, it might have an influence on life satisfaction. Therefore, life satisfaction of out-of-school youth and the factors related to it are public health concerns, even though Korea's dropout rate is lower than that seen in Western countries. Although the population of dropouts is small, the stigma, social isolation, and psycho-emotional problems they tend to experience (Lee \& Cho, 2017) are likely to have negative psychological and socioeconomic influences on these youth during adulthood (Kim et al., 2013); therefore, they should not be ignored.

Based on substantial worldwide literature on school dropouts, the likelihood of dropping out depends on multiple individual-, family-, school-, peer-, and society-related factors. Nearly half $(45.2 \%)$ of the studies published about out-ofschool adolescents in Korea focused on revealing the risk factors, $33.9 \%$ considered interventions to prevent it, and $4.8 \%$ focused on later career development (Kim \& Huh, 2012). One previous study found that adults' life satisfaction and depressive symptoms, among those who had been out-ofschool youth, were mediated by the extent of their depressive symptoms and life satisfaction when or shortly after they dropped out (Liem et al., 2010). However, the life satisfaction of out-of-school youth has been under-researched because of the challenges involved in finding participants or obtaining data from them after they leave school (Kim \& Huh, 2012).

The bivariate relationships in regression analyses between stigma, self-esteem, depressive symptoms, and life satisfaction have been well documented as being associated with dropping out of school and developmental outcomes (Civitci, 2010; Dupéré et al., 2018; Liem et al., 2010; Seaton et al., 2010). However, the influence of a sense of (or perceived) stigma on health outcomes needs further attention with regard to out-of-school youth in Korea. The mediating effect of self-esteem and depressive symptoms on the relationship between stigma and life satisfaction (Civitci, 2010) also need investigation in the Korean context. Knowledge about the reasons for dropping out might be important to educational policy and practice in Korea, and multidisciplinary efforts should be made to reduce the health problems related to dropping out of school. Investigating the life satisfaction of out-of-school youth, particularly those who perceive stigma, might support these efforts. While the risks of adverse outcomes (e.g., suicide) for youth in South Korea are higher compared with other countries regardless of school dropouts, dropping out may further exacerbate these risks. This study thus investigated the influences of stigma, self-esteem, and depressive symptoms on life satisfaction in a sample of out-of-school Korean youth and ascertained whether self-esteem or depressive symptoms mediated the relationship between stigma and life satisfaction.

In the present study, three hypotheses were formulated:

- Hypothesis 1: Stigma is negatively associated with life satisfaction in Korean youth who have left school.

- Hypothesis 2: Self-esteem mediates the negative association between stigma and life satisfaction.

- Hypothesis 3: Depressive symptoms mediate the positive association between stigma and life satisfaction.

\section{Methods}

\section{Participants}

The study used data derived from the 2017 Out of School Youth Survey (OSYS). The 2017 OSYS used a prospective panel design, and the National Youth Policy Institute (NYPI) annually obtains similar samples surveyed through the multi-youth center (NYPI, 2018). The NYPI conducted a cross-sectional survey with in-person interviews and self-report questionnaires based on the Act on the Support for Out-of-School Youth pursuant to Article 49 (4) of the Framework Act on Juveniles. The OSYS encompasses seven domains: educational disruption, life experiences, psychological and emotional characteristics, parental and peer relationships, everyday life and values, health risk behaviors, and socio-demographic characteristics. Attending elementary school was compulsory in Korea at the time of the survey. As such, individuals aged 16-24 years who had dropped out from any educational level higher than elementary school were considered eligible participants of this study. Informed written consent for the survey was obtained from adult participants, and from the parents or guardian of participants below the age of eighteen years, in accordance with the Bioethics and Safety Act.

Potential participants (776) responded to the recruitment announcement of the Ministry of Education and a private academy, 318 (40.97\%) completed the survey. These 318 respondents, aged 18-23, comprised the final sample, of which $52.5 \%(47.5 \%)$ were male (female). An institutional review 
board approved this study (no. 2019-0256). This study complied with the ethical principles of the Declaration of Helsinki, including amendments from 2000 to 2013.

\section{Measures}

\section{Dependent Variable}

A life satisfaction index for Koreans consisting of three items was used to measure life satisfaction. This life satisfaction scale was previously developed and validated (Kim et al., $2006)$ with response options on a four-point scale $(1=$ very dissatisfied to $4=$ very satisfied) for items such as "I am satisfied with my life overall" and "I like how my life is going." Higher scores indicate higher life satisfaction. The internal consistency for this measure was satisfactory (Cronbach's $\alpha=.79$, Spearman-Brown Coefficient $=.90$ ).

\section{Key Independent Variables}

The eight-item Korean Stigmatization Scale was previously translated and validated cross-culturally (Ju, 2002) from the Stigmatization Scale-Short (Harvey, 2001) and has been widely used for the Korean Children and Youth Panel Survey, except for two items that were difficult for adolescents to understand, based on the opinions of an expert panel. The two excluded items were "I'm viewed negatively by mainstream society" and "I feel that society views me as an inferior being." Responses were scored on a four-point Likert-type scale (from 1 = strongly disagree to $4=$ strongly agree). Higher scores on this scale indicate greater perception of stigma. The internal consistency for this measure was satisfactory $($ Cronbach's $\alpha=.87$, Spearman-Brown Coefficient $=.97)$.

The five-item Korean version of the self-esteem index was previously translated and validated (Research Institute of Behavioral Science in Korea University, 2000) from the 10-item Rosenberg Self-Esteem Scale (Rosenberg, 1979). The short version for Koreans uses five positive items, including "On the whole, I am satisfied with myself" and "I feel that I have a number of good qualities," with responses given on a four-point Likert-type scale (from $1=$ strongly disagree to $4=$ strongly agree). Higher scores indicate higher levels of selfesteem. The internal consistency for this measure was satisfactory (Cronbach's $\alpha=.87$, Spearman-Brown Coefficient $=.99$ ).

The 10-item Korean Depression Symptom Checklist-90 scale (Kim et al., 1978) was previously validated and used to measure depressive symptoms. Response options were scored on a four-point scale, ranging from 0 to 3 , to measure the severity and frequency of depressive symptoms such as "unpleasant thoughts" and "low energy." Higher scores indicate more depressive symptoms. The internal consistency for this measure was satisfactory (Cronbach's $\alpha=.91$, Spearman-Brown Coefficient $=.99$ ) .

\section{Other Independent Variables}

The analysis also included measures obtained from the participants' self-reports, and clinical records were used to collect information on age, sex, employment, and living arrangements. Family-level financial status was measured by responses to the question, "Do you think your family has sufficient money to cover your family expenses?" The response options ranged from $1=$ very insufficient to $7=$ very sufficient. Self-rated health was an overall measure based on responses to the question "How would you describe your general state of health?" The response options ranged from $1=$ very unhealthy to $4=$ very healthy.

\section{Data Analysis}

First, the study variables were analyzed using means and standard deviations or frequencies and percentages, depending on the variable. All statistical tests were performed using two-tailed tests of significance with a cut-off significance level of $p<.05$. Second, a hierarchical linear regression analysis was performed to test the effects of stigma, self-esteem, and depressive symptoms on life satisfaction. In Model 1, the influences of the six control variables (age, sex, employment, living arrangement, family-level financial status, and self-rated health) were estimated. Stigma, self-esteem, and depressive symptoms were added in Model 2. Third, path analysis and structural equation modeling were used to estimate the relationships among stigma, self-esteem, depressive symptoms, and life satisfaction. These included (1) the direct relationship between stigma and depressive symptoms and between depressive symptoms and life satisfaction, (2) the indirect relationships between stigma and self-esteem and between self-esteem and depressive symptoms, and (3) the overall direct and separate indirect effects of stigma on life satisfaction through self-esteem and through depressive symptoms. One thousand bootstrapped samples were analyzed using a 95\% confidence interval. The three goodness-of-fit indices were the root mean square error of approximation (RMSEA), goodness-of-fit statistic (GFI), and normed fit index (NFI). GFI and NFI values $\geq 0.90$ and RMSEA $<0.05$ and $\chi^{2} / \mathrm{df}(<2)$ were considered to indicate adequate model fit (Hooper et al., 2008). All analyses were performed using SPSS 23.0 (SPSS Inc., Chicago, IL, USA), except for the structural equation modeling, which was performed in AMOS 21.0 (SPSS Inc., Chicago, IL, USA).

\section{Results}

Table 1 presents the descriptive statistics for all the study variables. The participants' mean age was $20.67 \pm 1.17$ years, and there were more male (52.52\%) than female participants. Most of the participants lived with both parents $(70.13 \%)$ and perceived their financial situation as insufficient (38.36\%) and their health as poor $(24.84 \%$; Table 1$)$. 
Table 1 Descriptive statistics of the study variables $(N=318)$

\begin{tabular}{|c|c|c|}
\hline $\begin{array}{l}\text { Variable } \\
\text { Age (years) }\end{array}$ & $n(\%)$ & $\begin{array}{l}M(S D) \\
20.67(1.12)\end{array}$ \\
\hline \multicolumn{3}{|l|}{ Sex } \\
\hline Male & $167(52.52)$ & \\
\hline Female & $151(47.48)$ & \\
\hline \multicolumn{3}{|l|}{ Part-time job } \\
\hline Yes & $181(56.92)$ & \\
\hline No & $137(43.08)$ & \\
\hline \multicolumn{3}{|l|}{ Living with parents } \\
\hline Yes & $223(70.13)$ & \\
\hline No & $95(29.87)$ & \\
\hline \multicolumn{3}{|l|}{ Family-level financial status } \\
\hline Very insufficient & $10(3.14)$ & \\
\hline Moderately insufficient & $41(12.89)$ & \\
\hline Slightly insufficient & $71(22.33)$ & \\
\hline Neutral & $134(42.14)$ & \\
\hline Slightly sufficient & $45(14.25)$ & \\
\hline Moderately sufficient & $17(5.35)$ & \\
\hline \multicolumn{3}{|l|}{ Self-rated health } \\
\hline Very poor & $13(4.09)$ & \\
\hline Poor & $66(20.75)$ & \\
\hline Good & $195(61.32)$ & \\
\hline Very good & $44(13.84)$ & \\
\hline Life satisfaction (range $=3-12$ ) & & $7.77(1.82)$ \\
\hline Stigma $($ range $=8-25)$ & & $15.87(3.59)$ \\
\hline Self-esteem $($ range $=5-20)$ & & $14.84(2.51)$ \\
\hline Depressive symptoms (range $=9-36$ ) & & $18.84(5.22)$ \\
\hline
\end{tabular}

Note: $M=$ mean, and $S D=$ standard deviation
The index for the variance inflation factor was 1.02-1.38; multicollinearity was not identified; the Durbin-Watson test value was 1.99; and no autocorrelation existed between independent variables.

Table 2 shows the results of the hierarchical linear regression analysis estimating the effects of the control variables (Model 1) and the effects of stigma, self-esteem, and depressive symptoms on life satisfaction after controlling for the effects of sex, age, financial status, and living arrangements (Model 2). In Model 1, family-level financial status and self-rated health were found to be positively related to life satisfaction. In Model 2, the influence of family-level financial status was weakened; but it remained significant. However, the effect of self-rated health was weakened to nonsignificance. In addition, stigma and depressive symptoms were negatively related to life satisfaction, indicating that the higher the scores on these two variables, the lower the life satisfaction. Self-esteem had a positive influence on life satisfaction and had the strongest coefficient in the model. Model 1 explained approximately $25.8 \%$ of the variance in life satisfaction; this increased to $31.3 \%$ in Model 2 (Table 2).

All the Chi-square tests were significant $(p<.01)$, and the other fit indices were adequate $\left(\chi^{2} / \mathrm{df}=1.74 ; \mathrm{df}=1\right.$; RMSEA $=.05 ; \mathrm{GFI}=.99$; and NFI $=.99)$. Perceived stigma was significantly associated with two mediators: self-esteem $(\beta=-0.16, p$ $<.01)$ and depressive symptoms $(\beta=0.27, p<.01)$. Self-esteem was negatively associated with life satisfaction $(\beta=0.52, p<$ .01 ), and depressive symptoms were positively associated with life satisfaction $(\beta=-0.60, p<.01)$. Meanwhile, stigma was negatively associated with life satisfaction $(\beta=0.24, p<.01)$.

In addition, three variables (stigma, self-esteem, and depressive symptoms) accounted for $58.6 \%$ of the variance in life satisfaction in the full model, $(95 \%$ CI, $0.50-0.66$,
Table 2 Results of the hierarchical linear regression analysis of the relationships between stigma, self-esteem, and depressive symptoms and life satisfaction $(N=318)$

\begin{tabular}{|c|c|c|c|c|c|c|c|c|}
\hline \multirow[b]{2}{*}{ Variable } & \multicolumn{4}{|c|}{ Model 1} & \multicolumn{4}{|c|}{ Model 2} \\
\hline & $B$ & $\begin{array}{l}S E \\
(B)\end{array}$ & $\beta$ & $t$ & $\boldsymbol{B}$ & $\begin{array}{l}S E \\
(B)\end{array}$ & $\beta$ & $t$ \\
\hline Sex $(1=$ Male, $0=$ Female $)$ & -0.87 & 0.97 & -0.04 & 0.87 & 0.07 & 0.08 & 0.03 & 0.89 \\
\hline Age & -0.09 & 0.10 & -0.07 & 1.39 & -0.05 & 0.03 & -0.05 & 1.42 \\
\hline Family financial status & -0.06 & 0.04 & 0.32 & $6.30 * *$ & 0.15 & 0.04 & 0.17 & $4.13 * * *$ \\
\hline Self-rated health & 0.28 & 0.05 & 0.31 & $6.03 * *$ & 0.12 & 0.06 & 0.08 & 1.90 \\
\hline $\begin{array}{l}\text { Part-time job }(1=\text { Yes, } 0= \\
\quad \text { No) }\end{array}$ & 0.44 & 0.07 & 0.06 & 1.19 & 0.07 & 0.08 & 0.03 & 0.89 \\
\hline $\begin{array}{l}\text { Living arrangements }(1= \\
\quad \text { Yes, } 0=\mathrm{No})\end{array}$ & 0.12 & 0.10 & -0.02 & 0.49 & -0.10 & 0.08 & -0.05 & 1.24 \\
\hline Stigma & & & & & 0.11 & 0.04 & -0.11 & $2.77 *$ \\
\hline Self-esteem & & & & & 0.47 & 0.04 & 0.47 & $11.54 * * *$ \\
\hline Depressive symptoms & & & & & -0.38 & 0.04 & -0.38 & $8.64 * * *$ \\
\hline Adjusted $R^{2}$ & & & .26 & & & & .31 & \\
\hline$F$ & & & $17.88 * * *$ & & & & $74.16^{* * *}$ & \\
\hline
\end{tabular}

Note: $* * *$, and $* * *$ denote significance at the $5 \%, 1 \%$, and $0.1 \%$ levels, respectively, and SE means standard error 
$\left.p<.01, \mathrm{R}^{2}=0.59\right)$. The path model results revealed that stigma directly influences self-esteem and depressive symptoms. In addition, self-esteem and depressive symptoms have a direct impact on life satisfaction (as confirmed by 1000 bootstrapped samples). The standardized coefficients for the path model were all statistically significant $(p<.01)$.

Stigma had a positive direct effect on depressive symptoms ( $\beta=0.27, p<.01)$ and depressive symptoms had a negative direct effect $(\beta=-0.60, p<.01)$ on life satisfaction. Stigma had a negative direct effect on self-esteem $(\beta=-0.16, p<.01)$ and self-esteem had a positive direct effect $(\beta=0.52, p<.01)$ on life satisfaction. Stigma had a positive direct effect $(\beta=0.24$, $p<.01)$ and a negative indirect effect through self-esteem and depressive symptoms ( $\beta=-0.24, p<.01$ ) on life satisfaction. The bootstrapping test for the indirect effect of stigma on the relationship between stigma and life satisfaction showed a statistically significant association $(\beta=0.24, p<.01$, bias-corrected $95 \%$ confidence interval $=0.16-0.34$ ). Furthermore, the results revealed a significant indirect effect of stigma on life satisfaction, as transmitted through self-esteem and depressive symptoms. In other words, self-esteem and depressive symptoms mediated the relationship between stigma and life satisfaction, thereby supporting the study's hypothesis (Table 3).

Figure 1 illustrates the structural path model relationships among the key study variables. As expected, self-esteem and depressive symptoms mediated the relationship between stigma and life satisfaction. The results yielded a saturated model; all the estimates were significant, and the relationships were in the anticipated directions. The path from stigma to depressive symptoms revealed that depressive symptoms increased as perceived stigma increased, and the path from depressive symptoms to life satisfaction was the strongest of the three predictors (Fig. 1).

\section{Discussion}

To the best of my knowledge, this was the first nationally representative study on Korean out-of-school youth that examined the relationships among stigma, self-esteem, depressive symptoms, and life satisfaction with a focus on the

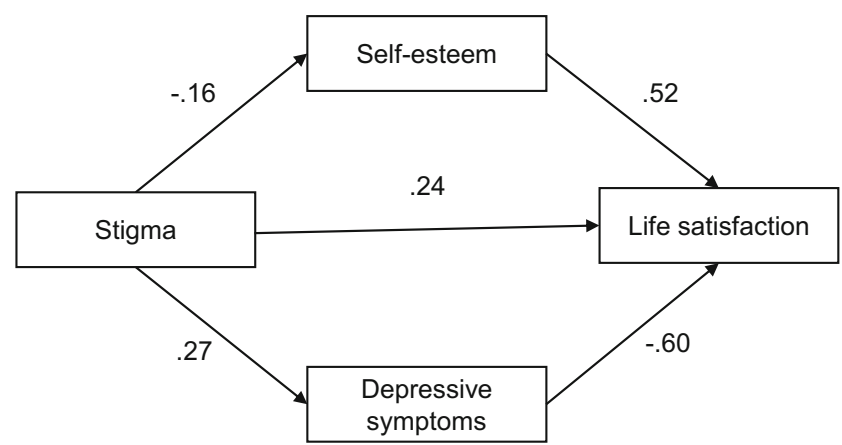

Fig. 1 Path analysis results among stigma, self-esteem, depressive symptoms, and life satisfaction

mediating effects of self-esteem and depressive symptoms. The findings particularly increase our knowledge about the influence of stigma on the lives of these youth.

Even after controlling for age, sex, and financial status, which affect self-esteem, depression, and life satisfaction, the factors that were found to influence life satisfaction were stigma, self-esteem, and depressive symptoms. The results were similar to the findings of the negative effects of stigma on life satisfaction among American adolescents with obesity, HIV, mental illness, or minority sexual status (Hatzenbuehler et al., 2013); those belonging to a racial minority (Seaton et al., 2010); and Turkish adolescents (Civitci, 2010). Specifically, these studies also showed positive (negative) effects of self-esteem (depressive symptoms) on life satisfaction (Civitci, 2010). Previous studies also reported that the effect of stigma diminished when the influence of self-esteem on life satisfaction was considered (Kim, 2018; Kim \& Park, 2019; Kim, 2019; Oliveira et al., 2016). Our findings also support a study of Korean college students (Kim et al., 2013), and the influence of stigma on depressive symptoms further supports prior results concerning vulnerable Singaporean youth (Pang et al., 2017). The current analysis revealed that stigma directly influences depressive symptoms, similar to a previous finding on self-stigma (Mickelson, 2001).

This effect on life satisfaction is strengthened with increasing levels of self-esteem, and a previous study in Turkey reported that self-esteem was a mediator of this relationship (Civitci, 2010). Apparently, self-esteem might mediate the
Table 3 Direct and indirect effects of social stigma on life satisfaction using 1000 bootstraps

\begin{tabular}{lllll}
\hline $\begin{array}{l}\text { Endogenous } \\
\text { variables }\end{array}$ & $\begin{array}{l}\text { Exogenous } \\
\text { variables }\end{array}$ & $\begin{array}{l}\text { Standardized direct } \\
\text { effect }\end{array}$ & $\begin{array}{l}\text { Standardized indirect } \\
\text { effect }\end{array}$ & $\begin{array}{l}\text { Standardized total } \\
\text { effect }\end{array}$ \\
\hline $\begin{array}{l}\text { Depressive } \\
\text { symptoms }\end{array}$ & Stigma & $0.27^{* * *}$ & & $0.28^{* * * *}$ \\
$\begin{array}{l}\text { Self-esteem } \\
\text { Life satisfaction }\end{array}$ & Stigma & $-0.16^{* * *}$ & $-0.16^{* * *}$ \\
Life satisfaction & $\begin{array}{c}\text { Depressive } \\
\text { symptoms }\end{array}$ & $-0.24 * * *$ & $-0.24 * * * *$ & $0.00^{* * *}$ \\
Life satisfaction & Self-esteem & $0.52^{* * * *}$ & & $-0.60^{* * *}$ \\
\hline
\end{tabular}

Note: $* *$ and $* * *$ denote significance at the $1 \%$ and $0.1 \%$ levels, respectively 
influence of perceived stigma on life satisfaction. If all of the above also apply to out-of-school youth in Korea, perceived stigma might lower self-esteem and diminish life satisfaction.

Those who had dropped out of school have lower self-esteem, lower life satisfaction, are more depressed, and are subject to greater stigma than those attending school. One study of Korean adolescents found that those who attended alternative schools (designed to provide a non-traditional educational experience) had significantly lower self-esteem and higher perceived stigma than adolescents who attended regular high schools (Cho et al., 2015). Because the expectations and priority of education are high, dropping out tends to be interpreted as leaving the competitive path to success. Out-of-school (including alternative school) youth might feel socially devalued, which might lower their self-esteem, increase their depressive symptoms, and consequently, lower their life satisfaction. Individuals who perceive stigma might avoid dropping out of school, particularly those who want employment, and the failure to gain employment might exacerbate depressive symptoms (Hjorth et al., 2016). Further, out-of-school youth who perceive stigma might disengage from their communities and curtail or stop their youth center activities to avoid people who may consider them failures. Community and youth center disengagement has been linked to exclusion and alienation from various forms of social support, such as counseling, training, and employment advice (NYPI, 2018).

The findings imply that although out-of-school youth might be relatively depressed and dissatisfied during adolescence, they are capable of rebounding if multiple efforts are made to lessen the sense of stigma, enhance self-esteem, and treat depressive symptoms to improve life satisfaction. A review of multi-level stigma interventions (interpersonal, organizational, and structural) found that they were relatively effective for stigma reduction and that they were more synergistic and more holistic than single-level interventions (Rao et al., 2019). The targeted multiple interventions among healthcare professionals, family members, and community members using various strategies (e.g., contact, social marketing, counseling, faith, and problem solving) were more effective than educational programs alone for reducing the sense of stigma. A meta-analysis of 52 self-esteem enhancement programs for children found a large overall effect of 0.89 , which was particularly large among the programs using music, painting, and other arts (1.29-1.72; Lee \& Chung, 2018). Regarding Korean middle school children, an experimental group that participated in 10 group sessions to treat high depressive symptoms showed significantly higher depressive symptoms and self-esteem than the control group (Cho \& Jang, 2016). Thus, depressive symptom screening and counseling of out-of-school youth should help improve their mental health and life satisfaction. As a whole, the evaluations of interventions and other programs suggest that the younger the participants, the more effective the intervention for self-esteem. However, programs with more than 10 sessions are negatively related to self-esteem; therefore, intervention programs for increasing self-esteem and reducing depressive symptoms must be appropriately developed to meet the developmental needs of children of specific ages.

Despite its contributions, this study has limitations to consider when interpreting the results. First, the participants were recruited by convenience sampling because of difficulties in identifying or locating out-of-school youth, which created an unknown extent of selection bias, thereby precluding the generalizability of the findings. The cross-sectional study design eliminated the possibility of drawing causal inferences about the relationships among the study variables. Moreover, this study focused only on psychological factors although other variables such as parent-child relationships, peer relationships, and academic performance influence the life satisfaction of the youth. Thus, it is necessary to investigate further these integrated and related factors. However, the findings on the mediating effects of self-esteem and depressive symptoms suggest that longitudinal research might shed light on the causal effect of stigma on life satisfaction and the mediating effects of self-esteem and depressive symptoms.

\section{Conclusions}

In conclusion, this study contributes to the literature about the life satisfaction of out-of-school Korean youth by identifying self-esteem and depressive symptoms as mediators of the relationship between stigma and life satisfaction. Improving self-esteem emerged as a possible way to decrease the influence of the perceived stigma on life satisfaction. Likewise, reducing depressive symptoms can also reduce the negative influence of stigma on life satisfaction. More research and policy attention should be devoted to monitoring the mental health of out-of-school youth and to developing interventions to reduce perceived stigma with the ultimate goal of decreasing depressive symptoms, increasing self-esteem, and improving life satisfaction of these adolescents. The current results have implications for multi-level support programs among community, employment, educational, and public health actors, and for interventions to protect out-of-school youth from developing a sense of stigma. Discrimination and social exclusion should be addressed by raising public awareness about out-of-school youth. Dropping out of school strongly determines adult outcomes and future inequities in educational attainment, employment, health, and life expectancy; thus, keeping children in school should be a broad policy priority.

Data Availability The datasets generated and/or analyzed in the current study are available from the corresponding author upon reasonable request. 


\section{Declarations}

Ethical Approval The participants provided informed written consent. An institutional review board approved this study (no. 2019-0256).

Competing Interests The author declares no conflict of interest

Open Access This article is licensed under a Creative Commons Attribution 4.0 International License, which permits use, sharing, adaptation, distribution and reproduction in any medium or format, as long as you give appropriate credit to the original author(s) and the source, provide a link to the Creative Commons licence, and indicate if changes were made. The images or other third party material in this article are included in the article's Creative Commons licence, unless indicated otherwise in a credit line to the material. If material is not included in the article's Creative Commons licence and your intended use is not permitted by statutory regulation or exceeds the permitted use, you will need to obtain permission directly from the copyright holder. To view a copy of this licence, visit http://creativecommons.org/licenses/by/4.0/.

\section{References}

Birchall, J. (2018). Early marriage, pregnancy and girl child school dropout. Retrieved April 11, 2020, from https://opendocs.ids.ac. uk/opendocs/handle/20.500.12413/14285.

Cho, G., Hwang, S., \& Kim, M. (2015). Building plan of an investigative study on the health status of out of school adolescents. The Korea Journal of Youth Counseling, 23(2), 61-85 https://www.kyci.or.kr/ fileup/lib_pdf/2015-119-4.pdf.

Cho, M., \& Jang, J. (2016). The effects of psychodrama group counselling on depression, self-esteem, stress and interpersonal relationship among middle school adolescents. The Korean Journal of Counseling and Psychotherapy, 28(2), 371-394. https://doi.org/10. 9728/dcs.2019.20.5.1001.

Civitci, A. (2010). Moderator role of self-esteem on the relationship between life satisfaction and depression in early adolescents. Emotional and Behavioural Difficulties, 15(2), 141-152. https:// doi.org/10.1080/13632752.2010.480885.

De Graaf, W., \& Van Zenderen, K. (2009). Segmented assimilation in the Netherlands? Young migrants and early school leaving. Ethnic and Racial Studies, 32(8), 1470-1488. https://doi.org/10.1080/ 01419870902763860.

Dupéré, V., Dion, E., Leventhal, T., Archambault, I., Crosnoe, R., \& Janosz, M. (2018). High school dropout in proximal context: The triggering role of stressful life events. Child Development, 89(2), e107-e122. https://doi.org/10.1111/cdev.12792.

Freudenberg, N., \& Ruglis, J. (2007). Reframing school dropout as a public health issue. Preventing Chronic Disease, 4(4), A107 https://pubmed.ncbi.nlm.nih.gov/17875251/.

Fujita, F., \& Diener, E. (2005). Life satisfaction set point: Stability and change. Journal of Personality and Social Psychology, 88(1), 158164. https://doi.org/10.1037/0022-3514.88.1.158.

Gaziel, M., Hasson-Ohayon, I., Morag-Yaffe, M., Schapir, L., Zalsman, G., \& Shoval, G. (2015). Insight and satisfaction with life among adolescents with mental disorders: Assessing associations with selfstigma and parental insight. European Psychiatry, 30(2), 329-333. https://doi.org/10.1016/j.eurpsy.2014.08.003.

Goffman, E. (2009). Stigma: Notes on the management of spoiled identity. Simon and Schuster.

Gottfried, M. A. (2014). Chronic absenteeism and its effects on students' academic and socioemotional outcomes. Journal of Education for
Students Placed at Risk (JESPAR), 19(2), 53-75. https://doi.org/10. 1080/10824669.2014.962696.

Harvey, R. D. (2001). Individual differences in the phenomenological impact of social stigma. The Journal of Social Psychology, 141(2), 174-189. https://doi.org/10.1080/00224540109600545.

Hatzenbuehler, M. L., Phelan, J. C., \& Link, B. G. (2013). Stigma as a fundamental cause of population health inequalities. American Journal of Public Health, 103(5), 813-821. https://doi.org/10. 2105/AJPH.2012.301069.

Hjorth, C. F., Bilgrav, L., Frandsen, L. S., Overgaard, C., Torp-Pedersen, C., Nielsen, B., \& Bøggild, H. (2016). Mental health and school dropout across educational levels and genders: A 4.8-year followup study. BMC Public Health, 16(1), 976. https://doi.org/10.1186/ s12889-016-3622-8

Hooper, D., Coughlan, J., \& Mullen, M. (2008). Structural equation modelling: Guidelines for determining model fit. The Electronic Journal of Business Research Methods, 6(1), 53-60 https://core.ac. uk/download/pdf/297019805.pdf.

Hunt, M. H., Meyers, J., Davies, G., Meyers, B., Grogg, K. R., \& Neel, J. (2002). A comprehensive needs assessment to facilitate prevention of school drop out and violence. Psychology in the Schools, 39(4), 399-416. https://doi.org/10.1002/pits.10019.

Ju, K. (2002). University students' intolerance of uncertainty on career barriers: Moderating effects of perfectionism. [unpublished master's thesis] Ewha Womans University.

Jung, T. (2010). Historical and cultural analyses of collective features of Korean society. The Korean journal of social and personality Psychology, 24(3), 53-76. https://doi.org/10.21193/kjspp.2010.24. 3.004 .

Keum, M. (2008). Comprehensive understanding about drop-out adolescents in Korea. Korean Psychological Association, 14(1), 299-317 https://www.kci.go.kr/kciportal/ci/sereArticleSearch/ ciSereArtiOrteView.kci?sereArticleSearchBean.artiId= ART001225726.

Kim, E. (2018). The risk factors of suicidal ideation according to age groups among the adolescents in Korea. Korean Journal of Health Promotion, 18(1), 42-50. https://doi.org/10.15384/kjhp.2018.18.1. 42.

Kim, H., \& Park, J. (2019). A qualitative research on school dropout experience of adolescents outside school: Focusing on pre-dropout, current dropout, post-dropout. Asia-Pacific Journal of Multimedia Services Convergent with Art, Humanities, and Sociology, 9(3), 119-130. https://doi.org/10.35873/ajmahs.2019.9.3.012.

Kim, H., \& Yang, M. (2017). A study on the social support, egoresiliency and stress coping strategies of school-dropout adolescents. Journal of Digital Convergence, 15(1), 23-34. https://doi. org/10.14400/JDC.2017.15.1.23.

Kim, K. (2019). A relationship between adolescents' self-esteem and depression: Comparison of data from 3 KCYPS surveyed for different periods. Journal of Adolescent Welfare, 21(2), 69-96. https:// doi.org/10.19034/KAYW.2019.21.2.03.

Kim, K., Oh, B., \& Lee. K. (2013). Policy research for suicide prevention of adolescents. Sejong.

Kim, K., Kim, J., Won, H., \& Kim, K. (1978). Standardization study of symptom check List-90 in Korea. Psychiatry Investigation, 17(4), 449-458 Retrieved April 18, 2020, from https://lib.nypi.re.kr/pdfs/ 2006/06.pdf.

Kim, Y., \& Huh, C. (2012). Research trends secondary school dropouts: 1991-2011. Korean Journal of Counseling, 13(2), 1013-1028. https://doi.org/10.15703/kjc.13.2.201204.1013.

Lee, J., \& Cho, Y. (2017). The relationship between perceived social support and career barriers among out-of school adolescents preparing for qualification examination for high school degree: Mediating effects of alienation. Journal of the Korea Academia-Industrial, 18(6), 90-102. https://doi.org/10.5762/KAIS.2017.18.6.90. 
Lee, S., \& Chung, I. (2018). A meta-analysis of self-esteem enhancement programs for children. Health and Social Welfare Review, 38(3), 45-74. https://doi.org/10.15709/hswr.2018.38.3.45.

Levine Coley, R., Eileen Morris, J., \& Hernandez, D. (2004). Out-ofschool care and problem behavior trajectories among low-income adolescents: Individual, family, and neighborhood characteristics as added risks. Child Development, 75(3), 948-965. https://doi.org/10. 1111/j.1467-8624.2004.00716.x.

Liem, J. H., Lustig, K., \& Dillon, C. (2010). Depressive symptoms and life satisfaction among emerging adults: A comparison of high school dropouts and graduates. Journal of Adult Development, 17(1), 33-43. https://doi.org/10.1007/s10804-009-9076-9.

Mashiach-Eizenberg, M., Hasson-Ohayon, I., Yanos, P. T., Lysaker, P. H., \& Roe, D. (2013). Internalized stigma and quality of life among persons with severe mental illness: The mediating roles of selfesteem and hope. Psychiatry Research, 208(1), 15-20. https://doi. org/10.1016/j.psychres.2013.03.013.

Mickelson, K. D. (2001). Perceived stigma, social support, and depression. Personality and Social Psychology Bulletin, 27(8), 10461056. https://doi.org/10.1177/0146167201278011.

Ministry of Gender Equality and Family. (2018). The white paper of youth in Korea 2018. Sejong. Retrieved April 11, 2020, from http://www.mogef.go.kr/mp/pcd $/ \mathrm{mp}$ ped s001d.do? $\mathrm{mid}=$ plc502\&bbtSn=704767.

Mustillo, S. A., Hendrix, K. L., \& Schafer, M. H. (2012). Trajectories of body mass and self-concept in black and white girls: The lingering effects of stigma. Journal of Health and Social Behavior, 53(1), 216. https://doi.org/10.1177/0022146511419205.

National Youth Policy Institute. (2018). A study on out-of-school youths. Retrieved April 18, 2020, from https://nypi.re.kr/brdrr/boardrrView. do? menu nix $=4$ o9 971 b $7 \&$ brd id=B D I D X PJk7xvf7L096m1g7Phd3YC\&cont_idx $=89 \&$ seltab_idx $=$ 0\&edomweivg $\mathrm{p}=\mathrm{R}$

Organisation for Economic Co-operation and Development (OECD). (2016). Society at a glance 2016-social indicators-a spotlight on youth. Retrieved April 11, 2020, from https://www.oecd-ilibrary. org/social-issues-migration-health/society-at-a-glance-2016 9789264261488-en

Oliveira, S. E., Carvalho, H., \& Esteves, F. (2016). Internalized stigma and quality of life domains among people with mental illness: The mediating role of self-esteem. Journal of Mental Health, 25(1), 5561. https://doi.org/10.3109/09638237.2015.1124387.

Pang, S., Liu, J., Mahesh, M., Chua, B. Y., Shahwan, S., Lee, S. P., Vaingankar, J. A., Abdin, E., Fung, D. S. S., Chong, S. A., \& Subramaniam, M. (2017). Stigma among Singaporean youth: A cross-sectional study on adolescent attitudes towards serious mental illness and social tolerance in a multiethnic population. BMJ Open, 7(10), e016432-2017-016432. https://doi.org/10.1136/bmjopen2017-016432.

Park, G., \& Kim, M. (2016). A comparative study of health status between students and out-of-school youth. Youth Facilities and Environment, 14(2), 17-26 https://www.earticle.net/Article/ A275514.
Park, N., \& Huebner, E. S. (2005). A cross-cultural study of the levels and correlates of life satisfaction among adolescents. Journal of CrossCultural Psychology, 36(4), 444-456. https://doi.org/10.1177/ 0022022105275961.

Pascoe, E. A., \& Smart Richman, L. (2009). Perceived discrimination and health: A meta-analytic review. Psychological Bulletin, 135(4), 531-554. https://doi.org/10.1037/a0016059.

Proctor, C. L., Linley, P. A., \& Maltby, J. (2009). Youth life satisfaction: A review of the literature. Journal of Happiness Studies, 10(5), 583630. https://doi.org/10.1007/s10902-008-9110-9.

Raimondi, E., \& Vergolini, L. (2019). Everyone in school: The effects of compulsory schooling age on drop-out and completion rates. European Journal of Education, 54(3), 471-490. https://doi.org/ 10.1111/ejed.12356.

Rao, D., Elshafei, A., Nguyen, M., Hatzenbuehler, M. L., Frey, S., \& Go, V. F. (2019). A systematic review of multi-level stigma interventions: State of the science and future directions. BMC Medicine, 17(1), 41. https://doi.org/10.1186/s12916-018-1244-y.

Research Institute of Behavioral Science in Korea University. (2000). Handbook of psychology (2). Hakjisa Publish Company.

Rosenberg, M. (1979). Conceiving the self. Basic Books.

Ross, A., \& Leathwood, C. (2013). Problematising early school leaving. European Journal of Education, 48(3), 405-418. https://doi.org/10. 1111/ejed.12038.

Scambler, G. (2009). Health-related stigma. Sociology of Health \& Illness, 31(3), 441-455. https://doi.org/10.1080/ 13548500600595053.

Seaton, E. K., Caldwell, C. H., Sellers, R. M., \& Jackson, J. S. (2010). An intersectional approach for understanding perceived discrimination and psychological well-being among African American and Caribbean black youth. Developmental Psychology, 46(5), 13721379. https://doi.org/10.1037/a0019869.

United Nations Educational, Scientific and Cultural Organization Institute for Statistics (UIS). (2019). New methodology shows that 258 million children, adolescents and youth are out of school. Retrieved April 11, 2020, from http://uis.unesco.org/sites/default/ files/documents/new-methodology-shows-258-million-childrenadolescents-and-youth-are-out-school.pdf.

Watkins, J. A., Sello, O. M., Cluver, L., Kaplan, L., \& Boyes, M. (2014). 'At school I got myself a certificate': HIV/AIDS orphanhood and secondary education: A qualitative study of risk and protective factors. Global Social Welfare, 1(3), 111-121. https://doi.org/10.1007/ s40609-014-0022-9.

Yun, C., Cho, E., Kim, G., Yu, S., Kim, T., \& Son, H. (2015). Panel survey of school dropouts and policy support for school dropouts III. Sejong: National Youth Policy Institute. Retrieved April 18, 2020, from https://www.nypi.re.kr/atchfile/prevealAtchfile.do? vchkcode $=2$ Bot3SJxmr9G.

Publisher's Note Springer Nature remains neutral with regard to jurisdictional claims in published maps and institutional affiliations. 